\title{
Hoferellosis in goldfish Carassius auratus and gibel carp Carassius auratus gibelio
}

\author{
Kálmán Molnár ${ }^{1}$, Theresia Fischer-Scherl ${ }^{2}$, Ferenc Baska ${ }^{1}$, Rudolf W. Hoffmann ${ }^{2}$ \\ ${ }^{1}$ Veterinary Medical Research Institute, Hungarian Academy of Sciences, H-1581 Budapest, Hungary \\ ${ }^{2}$ Institute of Zoology and Hydrobiology, University of Munich, D-8000 München 22, Federal Republic of Germany
}

\begin{abstract}
Hoferellus carassii is a common parasite of goldfish Carassius auratus and gibel carp C. auratus gibelio. Early trophozoite stages of $H$. carassii were found intracellularly, in epithelial cells of renal tubules. Plasmodial stages, however, had a coelozoic way of life, inhabiting the lumen of renal tubules, ureters and preferentially the urinary bladder. Spores were produced mostly in the latter site. No strict seasonality in development was established. In general, early stages were found during summer and autumn months, while spores occurred primarily from autumn to spring. In natural waters $H$. carassii infection of gibel carp passed without symptoms and only minor degenerations were recorded in kidney and urinary ducts. In goldfish from a pet fishpond, however, hoferellosis induced kidney enlargement disease, severe cystic transformation of tubules, and degeneration of the renal interstitium. Renal damage was caused by trophozoites invading the epithelial cells of renal tubules.
\end{abstract}

\section{INTRODUCTION}

Hoferellosis as a disease of the common carp was first reported by Plehn (1924) who identified the causative agent as Hoferellus cyprini (Doflein 1898). She described its histozoic and coelozoic stages, and presented data on its seasonal occurrence. Fujita (1912) identified spores similar to those of Doflein (1898). Fujita's description, however, is insufficient as he did not identify them to the $H$. cyprini level nor did he specify the typical host (his description concerned both common carp and goldfish). Recently Lom (1986) as well as Molnár et al. (1986) came to the conclusion that the genus Mitraspora was a junior synonym of the genus Hoferellus. Apart from Fujita's (1912) work, Achmerov (1960) was the first to describe a Hoferellus species from fish of the genus Carassius. He found these parasites in the urinary bladder of gibel carp Carassius auratus gibelio and described them as $H$. carassii. From the same fish Gavrilova (1966) also reported the occurrence of a Hoferellus species, which she described as $H$. conifer. Another species was identified in the gall bladder of the crucian carp C. carassius by Golikowa (1960) who designated it as $H$. schulmani. Lom (1986), who made a general revision of the genus Hoferellus and gave a detailed description of spores from common carp, gibel carp and goldfish, recognised only 2 valid species. In his opinion, $H$. cyprini only infects the common carp, while $H$. carassii is a common parasite of Carassius species, therefore, $H$. conifer and $H$. schulmani must be regarded as junior synonyms of H. carassii.

Hoferellosis, as a disease causing heavy losses in goldfish, was first studied by Ahmed (1973b) in Japan. He reported on this parasitosis under the name 'kidney enlargement disease'. Ahmed (1973a, b) identified the pathogen with Mitraspora cyprini and examined its development in fish and the pathogenesis of the disease in detail. Kidney enlargement disease was also detected in the USA by Hoffman (1984).

This paper reports on a survey of Hoferellus infection in the gibel carp and goldfish from Hungarian natural waters and fish farms. It is also a case report on kidney enlargement disease of goldfish in Bavaria. The paper presents data on the occurrence, development and pathogenicity of $H$. carassii.

\section{MATERIALS AND METHODS}

Forty-two specimens of gibel carp and 12 specimens of goldfish were examined for the presence of Hoferellus spores and developmental stages. Twenty gibel carp were seined in the River Körös, Hungary, and 17 
from a small creek running into the River Danube, Hungary, while 5 gibel carp and 5 goldfish were collected from the draining channel of a fish farm near Budapest. The remaining goldfish specimens came from the same ponds in Bavaria, FRG. Seven goldfish showing severe symptoms of a disease, were examined from a small pet fishpond.

Pieces of kidney and mucus obtained from the ureters and urinary bladder were examined, microscopically, in fresh preparations under a coverslip. For histological purposes, liver, spleen, gut, heart and gills (especially parts of kidney, ureters and the first part of the urinary bladder) were fixed in Bouin's fixative or in $10 \%$ buffered formalin and embedded in paraffin wax. Sections 4 to $6 \mu \mathrm{m}$ thick were stained with haematoxylin and eosin (H \& E), methylene blue and Giemsa's solution. Also, parts of the cystic kidney and portions of the apparently healthy trunk kidney of diseased goldfish were fixed in $6.25 \%$ phosphate buffered glutaraldehyde for 3 h, postfixed in $1 \%$ veronalacetate buffered osmium tetroxide, dehydrated in graded acetone series and embedded in Epon $812^{(3)}$. Semi-thin sections were stained with toluidine blue and safranine red. Ultra-thin sections were contrasted with uranyl acetate and lead citrate and examined in a Zeiss EM 109 electron microscope.

\section{RESULTS}

Thirty-seven of the 42 gibel carp from natural waters (10 to $17 \mathrm{~cm}, 14$ to $150 \mathrm{~g}$ ) and farm channels, and 2 of the 5 goldfish from farm channels were infected with Hoferellus plasmodia and spores. No infection was found in 7 goldfish cultured in fish farms. Spores from both gibel carp and goldfish (Fig. 1) corresponded to the description given by Lom (1986) of $H$. carassii. The prevalence of infection in gibel carp was high in the majority of cases, and the lumen of the urinary bladder of infected fish was filled with round or elliptical plasmodia 10 to $30 \mu \mathrm{m}$ (Fig. 2), with larger ones harbouring 1 to 4 spores each. Infection was less frequent in the ureters. In goldfish, prevalence was relatively low.

No seasonality was recorded in the occurrence of plasmodia and spores, but plasmodia without spores occurred most frequently during the autumn, while plasmodia with maturing spores were preferentially found in spring.

The majority of plasmodia adhered Ioosely to the wall of the urinary bladder (Figs, 2 and 3); a smaller part, however, was located freely in its lumen. Within plasmodia, mature and developing spores and sporoblasts were found simultaneously. Apart from dilation of the urinary bladder no pathological alterations were recorded

Intracellularly located Hoferellus trophozoites were found only in a single case - in a histological kidney section fixed in October. In this case, trophozoites were located in a given part of a single convoluted tubule (Fig. 4) and nearly every epithelial cell was infected. Trophozoites were located in the cytoplasm of the host cell apical to the nucleus (Fig. 5). In histological H \& E sections the diameter of round trophozoites was measured at 6.5 to $7.2 \mu \mathrm{m}$ and within trophozoites, 2 to 3 nuclei were detectable.

From April to November 1988 seven 2- to 3-yr-old goldfish (10 to $13.5 \mathrm{~cm}, 12.5$ to $25 \mathrm{~g}$ ) from a pet fishpond in Bavaria were examined for kidney myxosporeosis. More details are given in Fischer-Scherl \& Hoffmann (1989). During this time these fish developed characteristic kidney enlargement (bloater) disease.

Macroscopically, in 2 specimens examined in April, the kidney exhibited normal appearance. In histological sections numerous plasmodia were seen in the tubular lumen of the kidney. Two fish examined in July exhibited a swollen abdomen, due to an enlarged trunk kidney. In smear preparations a few spores of a Hoferellus species could be identified. In histological sections of apparently unaltered kidney tissue, plasmodia and maturing spores occurred in tubule lumens (Fig. 6). In epithelial cells, intracellular trophozoites were detected. Besides an abundance of fluid filling the lumen of convoluted tubules in the enlarged parts of the kidney, the collecting tubules were dilated and cystic transformation was observed. In August, the abdomen of 2 dissected goldfish were heavily swollen and they had difficulties in swimming. Both parts of the trunk kidney consisted of a conglomerate of large (up to $2 \mathrm{~cm}$ ) caverns (cysts) filled with fluid. In histological sections it was easy to see that these cystic structures were formed from dilated renal tubules. The cyst wall was composed of a proliferating, cylindrical epithelium and a basement membrane. In some parts, cysts were also bordered by several layers of connective tissue. In the less altered portion of kidney (Fig. 7), the renal interstitial cells more or less preserved their original shape and size under the cystically enlarged epithelium, but in more severely affected portions the remainder of the renal interstitium was sandwiched

Figs. 1 to 4. Hoferellus carassi. Fig. 1 Spores in gibel carp Carassius auratus gibello (a, b, c) and goldfish C. auratus (d). Spores in $c$ and $d$ with extruded filaments, $\times 2000$. Fig. 2. Plasmodia attached to the epithelium and filling the lumen of the urinary bladder (u) of $C$ auratus gibelio. $\mathrm{H} \& \mathrm{E}, \times 1000$. Fig. 3. Plasmodia attaching to epithelial cells $(\mathrm{ec})$ of the urinary bladder of $C$. auratus gibelio contain developing sporoblasts. $H \& E, \times 1500$. Fig. 4. C. auratus gibelio renal tubules infected with intracellular trophozoites ( $\star$ ?. $H \& E_{1} \times 200$ 

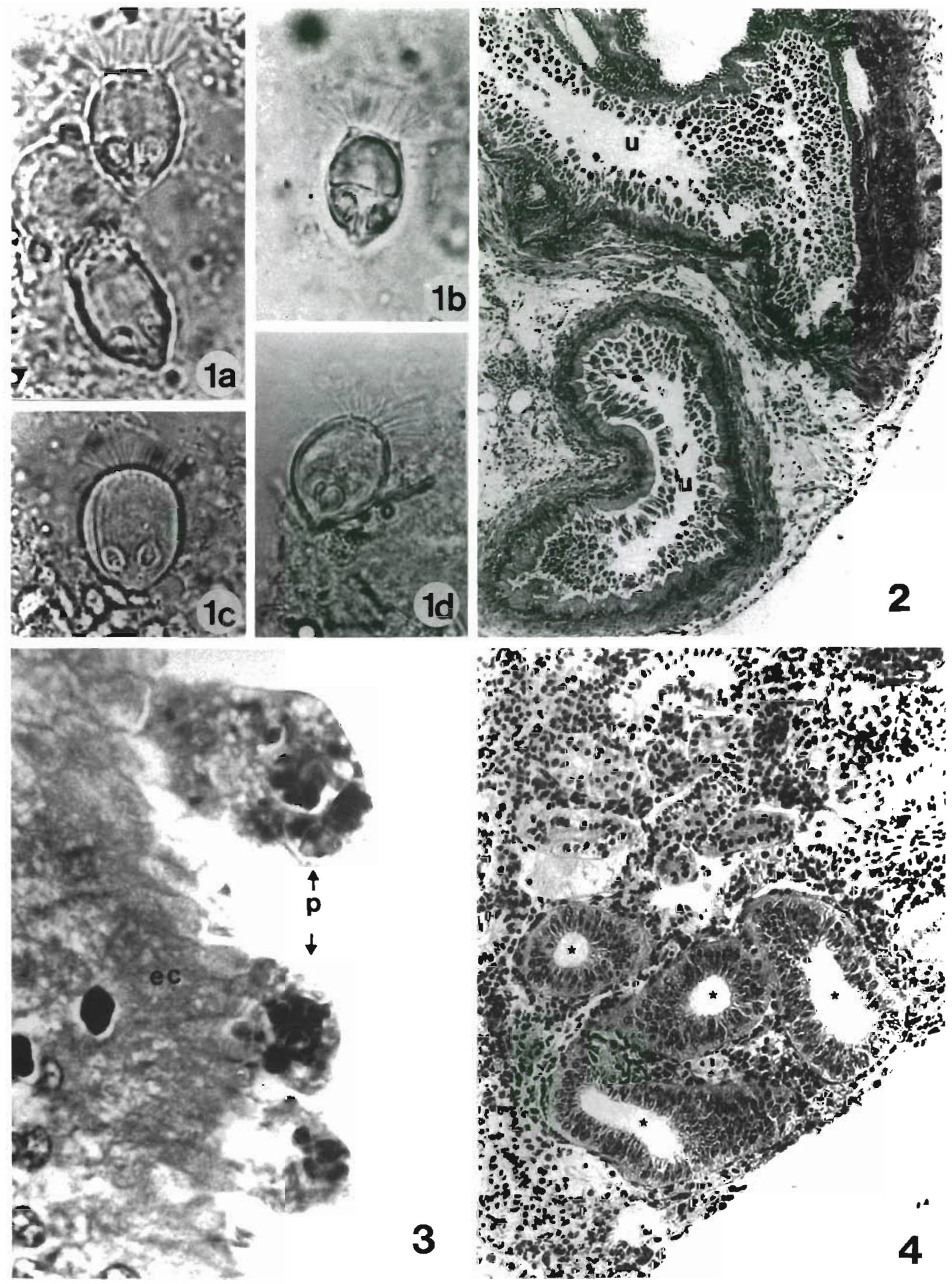


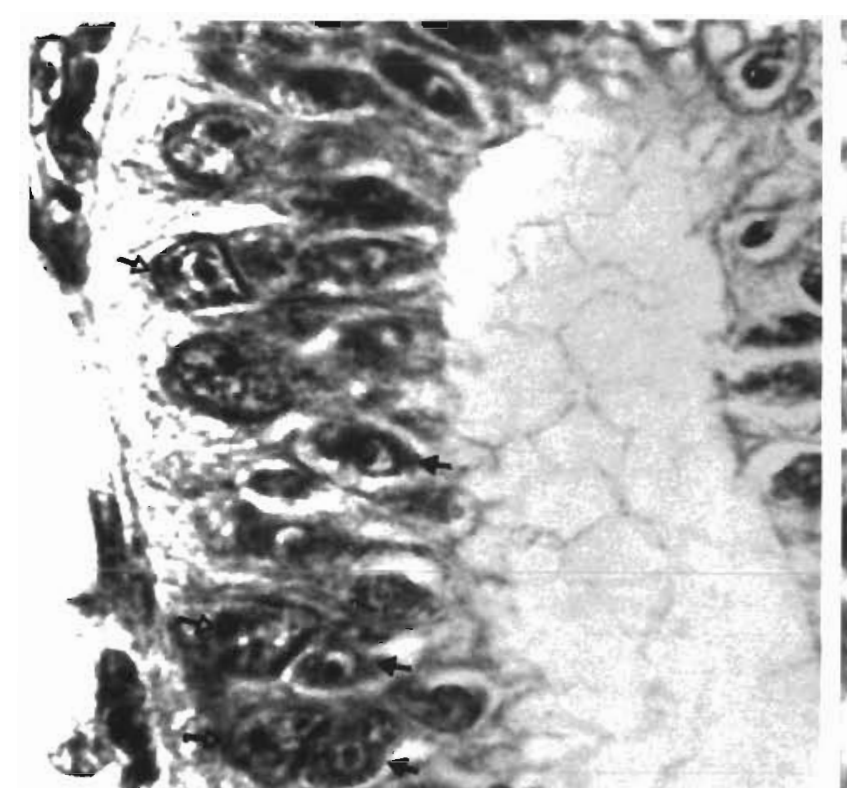

2. 1 is
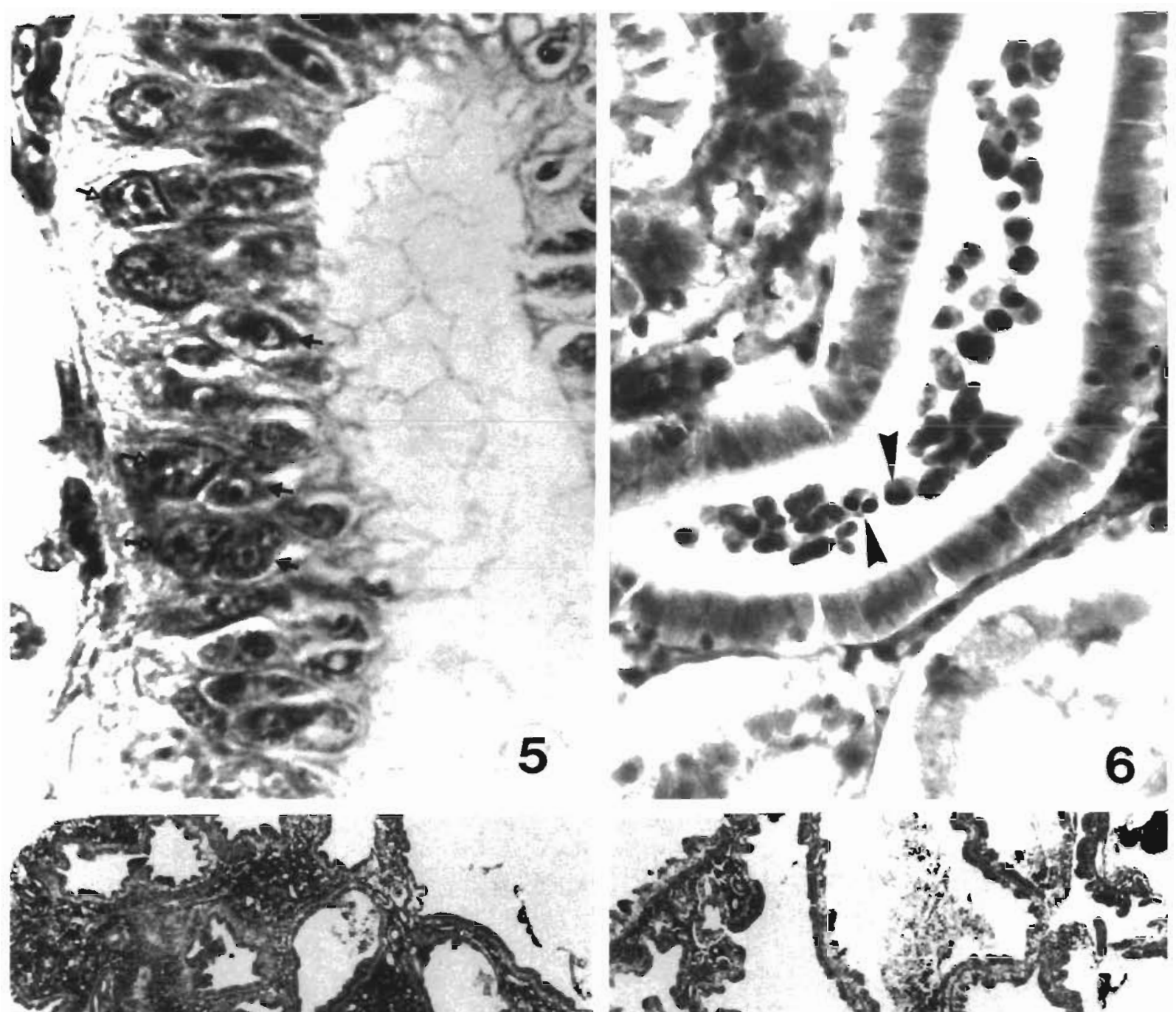

5 - inter 6

H

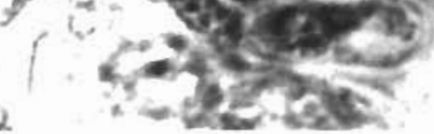

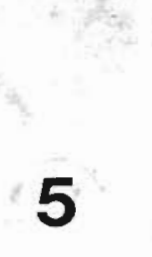


between the epithelia of 2 neighbouring caverns (Fig. 8). In histological sections, neither plasmodia nor spores were found in the lumen of cysts, although in fresh preparations some spores of a Hoferellus species were detected. At the same time, both in histological sections (Figs. 7 and 8) and in semithin sections (Fig. 9), it could be seen that every cell of the cylindrical epithelium lining the cysts was infected by myxosporean developmental stages. These trophozoites were located apical to the nucleus, in the cytoplasm of the host cells. Electron microscopy revealed that these trophozoites were composed of 1 or 2 cells. In stages composed of 2 cells, the cytoplasm of the larger (primary) cell surrounded the smaller (secondary) (Fig. 10). All infected epithelial cells were lined by intact cell membranes, and syncytia of the parasite-infected cells were never observed.

Cystic transformation of kidney and infection of epithelial cells of cysts with trophozoites were detected even in the 1 goldfish examined in November. In $\mathrm{H}$ \& E-stained sections, myxosporean stages appeared as black dots in the metaplastic epithelium of infected tubules (Fig. 11). At that time, in fresh preparations, a large number of plasmodia and mature spores of a Hoferellus species (Fig. 1d) were detected in the lumen of cysts. Besides in the trunk kidney, plasmodia and spores were also found in ureters and the urinary bladder. Spores found in these locations corresponded to $H$. carassii Achmerov 1960, as it was redescribed and depicted by Lom (1986).

\section{DISCUSSION}

This study has shown that Hoferellus infection occurs frequently in gibel carp and goldfish in natural waters and in populations kept as pet fish in small ponds. It has also been demonstrated that even heavy infections fail to produce disease symptoms in fish of natural waters, in contrast to those small ponds where hoferellosis may induce heavy losses.

The causative agent of hoferellosis in gibel carp and goldfish differs from Hoferellus cyprini both in morphological and biological respects. Therefore, we share Lom's (1986) opinion that Hoferellus carassii Achmerov, 1960 is a valid species, which infects members of the Carassius genus. Spores of $H$. carassii differ from those of $H$. cyprini by their conical protuberances at the anterior. This feature led Gavrilova (1966) to describe this species as $H$. conifer. The fact that both gibel carp and goldfish are subspecies of $C$. auratus prompted us to accept the view that these fish are infected by only 1 Hoferellus species, which we identify with $H$. carassii.

The first, intracellular phase of the development of Hoferellus carassii takes place in the tubular epithelium of kidney. In this phase, the early development stages are represented by unicellular trophozoites infecting the cytoplasm of epithelial cells. More developed trophozoites are already composed of 2 or 3 cells. In the latter case the second and third parasitic cells are found inside the cytoplasm of the first, and this fact clearly shows that they were formed by internal cleavage of the primary cell. Unfortunately, so far, no observations have been made as to how and when these intracellular trophozoites leave the host cells.

The second, coelozoic. phase of development takes place in the lumen of urinary ducts. In gibel carp the whole coelozoic development took place in the urinary bladder. In goldfish, however, plasmodia and spores were also found in upper urinary ducts (renal tubules, ureters).

From histological sections, it is difficult to identify myxosporean parasites exactly. Therefore, plasmodia and developing spores found in April, and those observed in renal tubules of unaltered kidney in July were unsuitable for clearly identifying the parasites as stages of Hoferellus carassii. However, in fresh preparations of altered renal tissue, spores of $H$. carassii were clearly proven. Nevertheless, for April and July we cannot exclude an infection by a Sphaerospora sp., a very common parasite of these fish.

The development of Hoferellus carassii is similar to that of H. cyprini (Kovács-Gayer et al. 1987) in common carp (Cyprinus carpio). Both parasites have an intracellular stage in the tubular epithelium and a coelozoic stage in the lumen of tubules, ureters and/or urinary bladder, and a stage of spore maturation. However, there are important differences in the biology of the 2 species. The development of $H$. cyprini is characterized by a distinct seasonal cycle, in which the intracellular stage takes place during the autumn, the plasmodial stage in winter, and the maturation of spores in April. In $H$. carassii, plasmodia and spores can be found in all seasons, while intracellular stages preferentially occur in summer and autumn. The structure of the affected renal tissue also differs depending on which Hoferellus

Figs. 5 to 8. Hoferellus carassi. Fig. 5. Section of infected renal tubule of Carassius auratus gibelio. Each epithelial cell harbours a trophozoite $(\uparrow)$ apical to the nucleus ( $r) . H \& E, \times 1000$. Fig. 6. Maturing spores ( 1 ) and plasmodia in the lumen of renal tubules of a

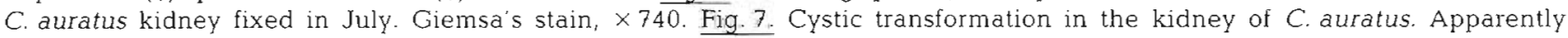
unchanged kidney tissue $(\mathrm{kt})$ is left between the cystically enlarged epithelia ( 1 ) harbouring trophozoites ( $*$ ). H \& E, $\times 45$. Fig. 8 . Cystic transformation in the kidney of $C$. auratus. Hardly any remnants of kidney tissue are left between cystically enlarged epithelia (*). H \& E, $\times 35$ 
species is involved. In $H$. cyprini infection, the nodule in a given part of the kidney is formed by a syncytial fusion of epithelial cells infected by trophozoites (Lom and Dyková 1985). In $H$ carassii infection, every epithelial cell is attacked by a single (or occasionally 2 trophozoites). In this respect $H$. carassii infection is
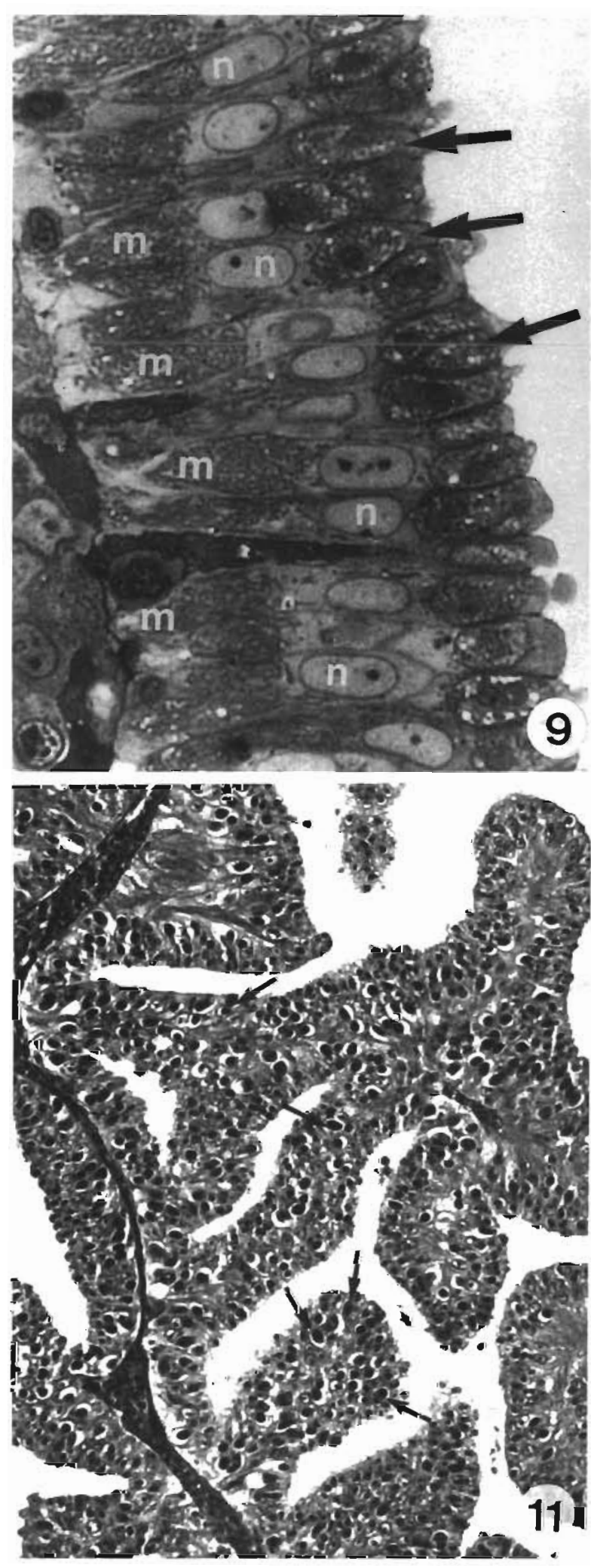

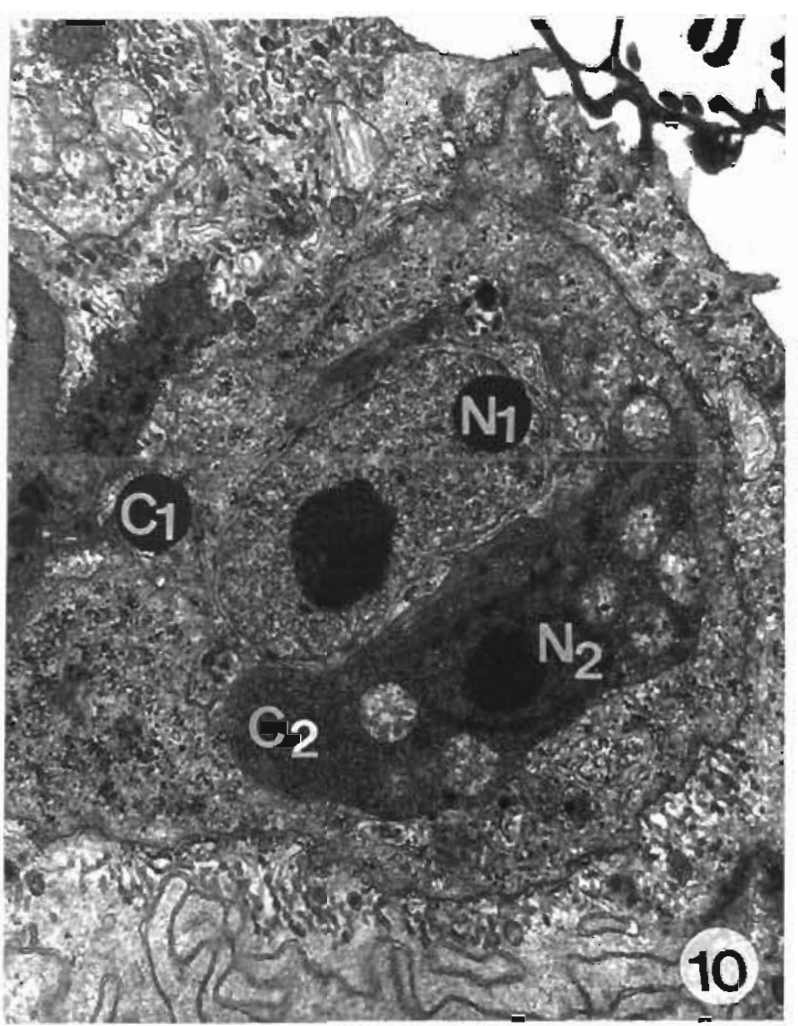

Figs. 9 to 11 Hoferellus carassii. Fig. 9. Epithelial cells of Carassius auratus with the cyst's epithelium harbouring early developmental stages ( $\uparrow$ ) at the apex. Note the light shining host cell nucleus ( $\mathrm{n}$ ) with distinct nucleolus. Numerous mitochondria $(\mathrm{m})$ are located at the base of the cells. Semithin section, toluidine-safranine, $\times 900$. Fig. 10. Two-cell-stage trophozoite in C.auratus. The cytoplasm of the primary cell incorporates the secondary cell. $\mathrm{C}_{1}$ : primary cell cytoplasm; $N_{1}$ primary cell nucleus; $C_{2}$ secondary cell cytoplasm; $N_{2}$ secondary cell nucleus. TEM, $\times 13500$. Flg. 11 . In November advanced development stages ( $\uparrow$ ) could be detected easily in the metaplastic cyst epithelium of $C$. auratus. $H \& E_{i} \times 220$ 
more similar to Myxobilatus infection (Molnár 1988) than to hoferellosis of the common carp

During our study of goldfish, we found the same symptoms described by Ahmed $(1973 a$, b) and Hoffman (1984), and we are of the opinion that kidney enlargement disease is caused by Hoferellus carassii. The present study provides evidence that early stages of the parasites in epithelial cells of cysts induce the transformations. It is still not known, however, whether cystic transformation of the kidney is caused directly by intensive proliferation of the tubular epithelium, or if cysts are a secondary consequence of this proliferation resulting in mechanical blockage of efferent parts of tubules thereby obstructing the flow of excreted fluid.

Acknowledgements. The authors wish to thank Miss B Klumpp and Miss Ch. Kühnhauser for excellent technical assistance and Mrs H. Mayer for typing the manuscript.

\section{LITERATURE CITED}

Achmerov, A. Kh. (1960). Myxosporidia of fishes from the Amur River basin. Rȳb. Khoz. vnutr. vod. LatSSR 5 240-307 (Russian)

Ahmed, A. I A. (1973a). Morphology and life history of Mitraspora cyprini Fujita parasitic in the kidney of goldfish. Jpn. J, med. Sci. Biol. 26: 87-101

Ahmed, A. T A. (1973b). Kidney enlargement disease in goldfish in Japan. Jap. J. Zool. 17: 37-57

Doflein, F. (1898). Studien zur Naturgeschichte der Protozoen.

Responsible Subject Editor: Professor W. Körting, Hannover, F.R. Germany
IIl. Über Myxosporidien. Zool. Jb. (Abt. Anat. Ontog. Tiere) 2: 281-350

Fischer-Scherl, T., Hoffmann, R. (1989). Zur zystischen Nierenerkrankung in einer Goldfischpopulation. DVG Verhandlungsband, Tagung der Fachgruppe Fischkrankheiten. München, 22.-23. November 1988, in press

Fujita, T (1912). Notes on new sporozoan parasites of fishes. Zool. Anz. 37: 251-261

Gavrilova, N. G. (1966). New myxosporidium species from gibel carp in Kairak-Kymsky water reservoir In: Bolezni rib i meri borbi s nimi. Alma-Ata, p. 58-59. (In Russian)

Golikowa, M. N. (1960). Eco-parasitologic examinations of the biocoenosis of some lakes in the Kaliningrad district. Vestn. Leningr Univ. Biol. 2: 110-121

Hoffman, G. L. (1984). Two fish pathogens, Parvicapsula sp. and Mitraspora cyprini (Myxosporea) new to North America. Symp. Biol., Hung. 23: 99-118

Kovács-Gayer, E., Ratz, F., Baska, F., Molnár, K. (1987). Light and electron microscopic studies on various developmental stages of Hoferellus cyprini (Doflein 1898). Eur J. Protist. 23: 185-192

Lom, J (1986). Hoferellus cyprini (Doflein 1898) Berg 1989 (Syn. Mitraspora cyprini Fujita 1912) Myxobilatus nostalgicus sp. $\mathrm{n}$. and related species: partial revision of two myxosporean genera. Folia parasitol (Prague) 33: 289-296

Lom, J., Dyková, I. (1985). Hoferellus cyprini Doflein, 1898 from carp kidney: a well established myxosporean soecies or a sequence in the developmental cycle of Sphaerospora renicola Dyková et Lom, 1982. Protistologica 21: 195-206

Molnár, K. (1988). Development of Myxobilatus legeri in cyprinid fishes. Dis. aquat. Org. 4: 181-187

Molnár, K., Csaba, Gy., Kovács-Gayer, E. (1986). Study of the postulated identity of Hoferellus cyprini (Doflein 1898) and Mitraspora cyprini Fujita, 1912. Acta Vet. hung. 34: 175-181

Plehn, M. (1924). Praktikum der Fischkrankheiten. Schweitzerbartsche Verlagsbuchhandlung, München

Manuscript first received: April 12, 1989

Revised version accepted: August 4, 1989 